EVIDENCE BASED PUBLIC HEALTH POLICY AND PRACTICE

\title{
Did Finland's Tobacco Control Act of 1976 have an impact on ever smoking? An examination based on male and female cohort trends
}

\author{
S Helakorpi, T Martelin, J Torppa, K Patja, E Vartiainen, A Uutela
}

J Epidemiol Community Health 2004;58:649-654. doi: 10.1136/jech.2003.015925

See end of article for
authors' affiliations
$\ldots \ldots \ldots \ldots \ldots \ldots \ldots . . . .$.
Correspondence to:
MSc S Helakorpi, National
Public Health Institute
(KTL), Mannerheimintie
166, FIN-00300 Helsinki,
Finland;
satu.helakorpi@ktl.fi
Accepted for publication
22 December 2003

\begin{abstract}
Objective: To examine patterns of ever smoking among Finnish adults by gender and birth cohort from 1978 to 2001, with special emphasis on the possible effects of the 1976 Tobacco Control Act (TCA).

Methods: The data were derived from independent, annual cross sectional postal surveys among 15-64 year olds $(n=91342)$, average response rate 75\%. For the analyses 13 five year birth cohorts from 1916 to 1980 were constructed. Birth cohort variations in ever regular smoking were first examined graphically, and then logistic models were used to test the impact of the TCA.

Results: Among men there was a decrease in smoking from older to younger cohorts. For women an increase in smoking was observed between successive cohorts. A clear decline in the prevalence of ever smokers concurrent with the TCA was found among both men and women.

Conclusions: The smoking behaviour trends across successive birth cohorts suggest the impact of tobacco policy in decreasing smoking initiation in youth. These findings thus support the acceptability and effectiveness of antismoking and smoke free policy measures in society.
\end{abstract}

$\mathrm{T}$ obacco smoking is a major cause of premature death in industrialised countries, being a risk factor for cardiovascular diseases, chronic obstructive pulmonary disease, and cancer, ${ }^{12}$ among others. Smoking causes about $35 \%$ of all male and $12 \%$ of all female deaths among 35-69 year olds in developed countries. ${ }^{3}$

Industrial manufacture of cigarettes has boosted the prevalence of smoking in epidemic fashion, reaching a prevalence of $50 \%$ or more in adult male populations in many countries..$^{4-7}$ The trend in Finland has been broadly similar to that in other Western countries. ${ }^{8}$ The main exception is that Finland already had many cigarette factories back in the 19th century, which led to Finnish men consuming more factory made cigarettes than anywhere else at the beginning of the 20th century. ${ }^{9}$

The prevalence of smoking in the Finnish adult male population was close to $70 \%$ until the 1950s, subsequently declining to about $45 \%$ in 1965-70. In contrast, Finnish women smoked little; at the beginning of the 1960s the prevalence was 13\%. ${ }^{10}$ From 1978 to 2001, male smoking declined from $36 \%$ to $29 \%$, while female smoking increased from $17 \%$ to $20 \% .^{11}{ }^{12}$

Nowadays, tobacco consumption in Finland is among the lowest in Europe. ${ }^{13}$ Antismoking activities in Finland began in the 1960s. In 1964 the National Board of Health published its first report, modelled on the US surgeon general's report. ${ }^{14}$ In 1966 the Finnish Tobacco Committee proposed the restriction of both cigarette advertising and smoking in public places. In 1969 the tobacco industry voluntarily stopped advertising its products on television, and this was banned in 1970. The Second Tobacco Committee for pre-legislative work was nominated in 1972 and the Finnish Tobacco Control Act (TCA) was passed in 1976. The TCA prohibited smoking in most public places and on public transport, restricted tobacco advertising, and set a 16 year age limit for tobacco purchases. Manufacturers were obliged to include health warnings on tobacco packaging, and about $0.5 \%$ of tobacco tax revenue was allocated to tobacco control programmes and other health promotion initiatives. A total advertising ban was enforced in 1978. ${ }^{15-18}$
Tobacco excise taxes have been widely promoted as an effective tobacco control policy tool to encourage quitting, reduce consumption among remaining smokers, and decrease smoking initiation. Although tobacco prices in Finland were raised substantially in 1975-1976, subsequent annual increases have been either modest or negligible. ${ }^{19}$ Various other tobacco control policy measures were implemented during the 1980s. Prevention programmes started in the North Karelia project from $1972^{20}$ gradually spread nationwide.

Assessment of the effect of tobacco control measures on smoking prevalence requires that policy is analysed in the context of societal processes, together with detailed and comprehensive information on smoking trends. In principle, changes in daily smoking prevalence may arise either from periodical change or from disparate developments in successive birth cohorts. Rates of smoking initiation may vary, leading to persistent disparities in the proportion of ever smokers between birth cohorts. Such differences have been suggested by earlier Finnish studies. For example, the peak proportion of male ever regular smokers has been located in cohorts born in 1911-25, while the first female group to adopt smoking more widely appears to be those born during the second world war (in 1941-45). ${ }^{10} 2122$ On the other hand, smoking cessation affects the proportion of daily smokers within each cohort.

This study analysed trends in ever smoking among adult Finns and their associations with the 1976 TCA. The dataset covers the period 1978-2001, which enabled us to examine the variation of smoking initiation rate via the patterns of ever regular smoking by successive male and female birth cohorts. Our baseline hypothesis was that any impact of the TCA would manifest as a lower initiation rate than could otherwise be expected among birth cohorts that entered the critical age range after the TCA became effective. More specifically, we expected no effects on the prevalence of ever regular smoking among cohorts that had already passed their 21st birthday in 1976 (born 1955 or earlier), a gradually increasing effect among those born in 1956-60, and a full effect among those born in 1961 or later. 


\section{METHODS}

\section{Data collection}

Since 1978, Finland's National Public Health Institute (KTL) has monitored health behaviour among the adult population by independent, annual cross sectional postal surveys. Each year a random sample $(n=5000)$ of Finnish citizens aged 15-64 years has been drawn from the Population Register. The questionnaire, consistently mailed between April and June with two reminders in 1978-1998 and three reminders in 1999-2001, has remained essentially the same over the years. The average, albeit declining, response rate has been $70 \%$ among men and $80 \%$ among women. In the entire study data the number of men was 43809 and of women 47533 (table 1). From 2002 telephone interview information (collected by the Survey Research Unit of Statistics Finland) on non-respondents' smoking habits has been used to correct any effect of the decreased response rate (see appendix).

For the analyses 13 five year birth cohorts were constructed. Persons belonging to the oldest birth cohort were born in 1916-20 and those comprising the youngest one in 1976-80. Seven of the birth cohorts (1936-40 to 1966-1970) were followed up through the entire 24 year period.

\section{Definition of smoking status}

Respondents' smoking status was obtained by self administered questionnaire, using two, and since 1996 three, questions: "Have you ever smoked?" (every year), "Have you ever smoked regularly (that is, almost every day for at least one year)" (pre-1996), and "Have you ever smoked daily for at least one year?" and "Have you ever smoked at least 100 times?" (post-1996). Those who reported smoking regularly/daily for at least one year, and at least 100 times, were regarded as ever regular daily smokers.

\section{Statistical methods}

Variations in smoking by age, cohort, and period were first examined graphically for both sexes. Thereafter, logistic regression was applied to assess the independent contributions of age, cohort, and the 1976 TCA.

Because the response rate declined over the study period, especially in recent cohorts, the resulting bias was corrected for in the logistic models (see appendix for correction procedures).

Among both sexes the probability of being an ever regular smoker increased with age up to 25 years, indicating a rather stable pattern of smoking initiation (fig 1). Cases aged less than 19 years were excluded. Figure 1 depicts the age profile for all birth cohorts and both sexes modelled by a continuous line that is ascending in the age range 19-25 years, horizontal from 25 to 49 years, and descending thereafter; the latter phenomenon may partly reflect the effect of selective mortality. The slopes of the ascending and descending parts of the line were modelled by two special age variables (see footnote to table 2).

The general cohort trends over time were a decrease in male smoking and an increase in female smoking. Previous studies have shown that certain cohorts deviated from the general linear trends, ${ }^{21}{ }^{22}$ - that is, those born in 1916-1925 (reached smoking initiation age during the second world war), in 1931-35 (reached smoking initiation age in the post-war economic depression), and in 1946-50 (the "baby boomer" generation). Dummy variables were included in the model to take into account these three cohorts. The hypothesised effect of the TCA was included in the models on a sliding scale: for the cohort born in 1956-60 the effect was allowed to increase by $20 \%$ per birth year, while for cohorts born in 1961 or later the effect was assumed to be $100 \%$. In addition, the interaction between the TCA variable and birth cohort was included in the model.

Table 1 Number of respondents and participation rates in Finland's annual adult health behaviour survey, by study period, sex, and five year birth cohorts

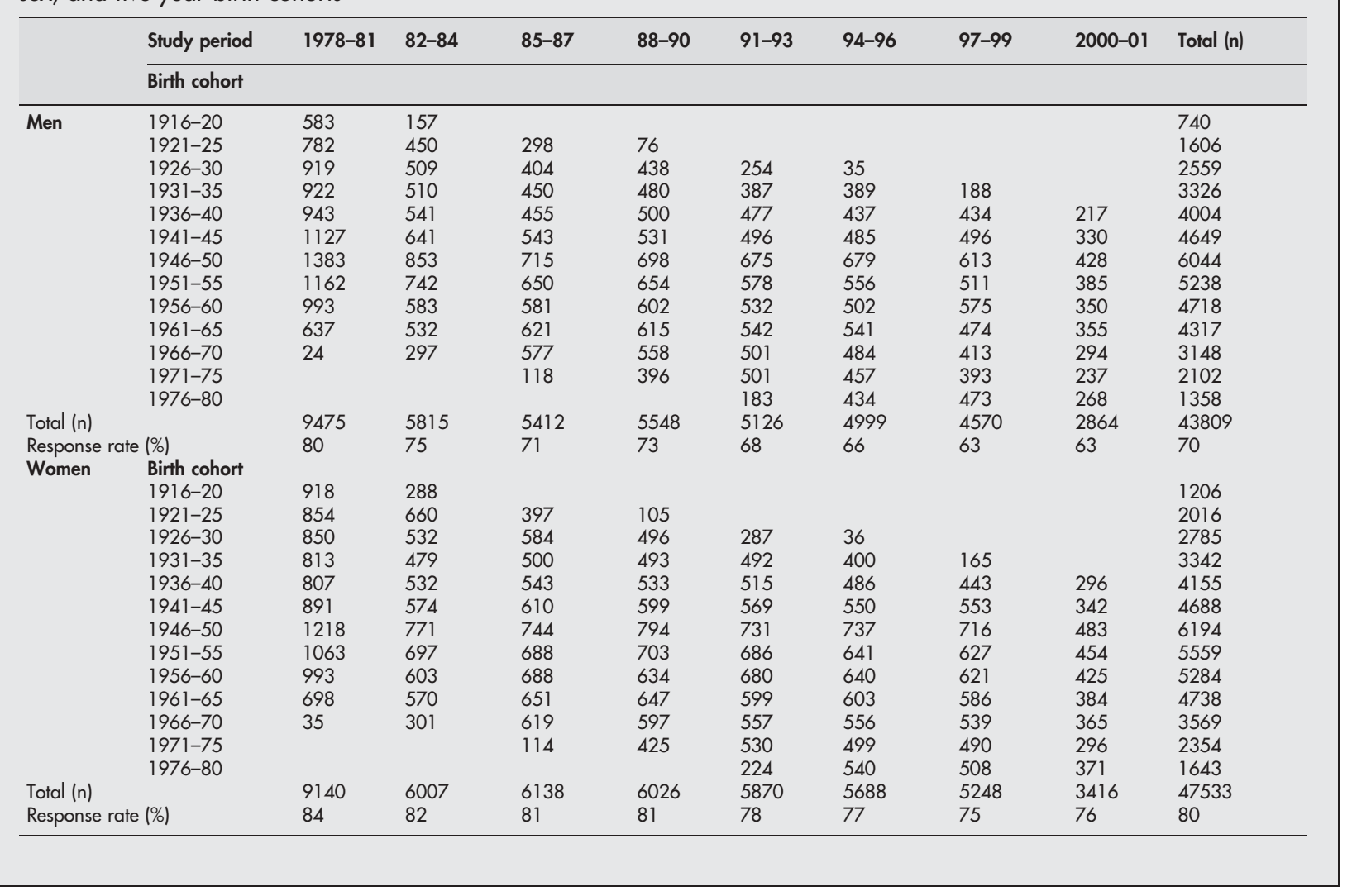



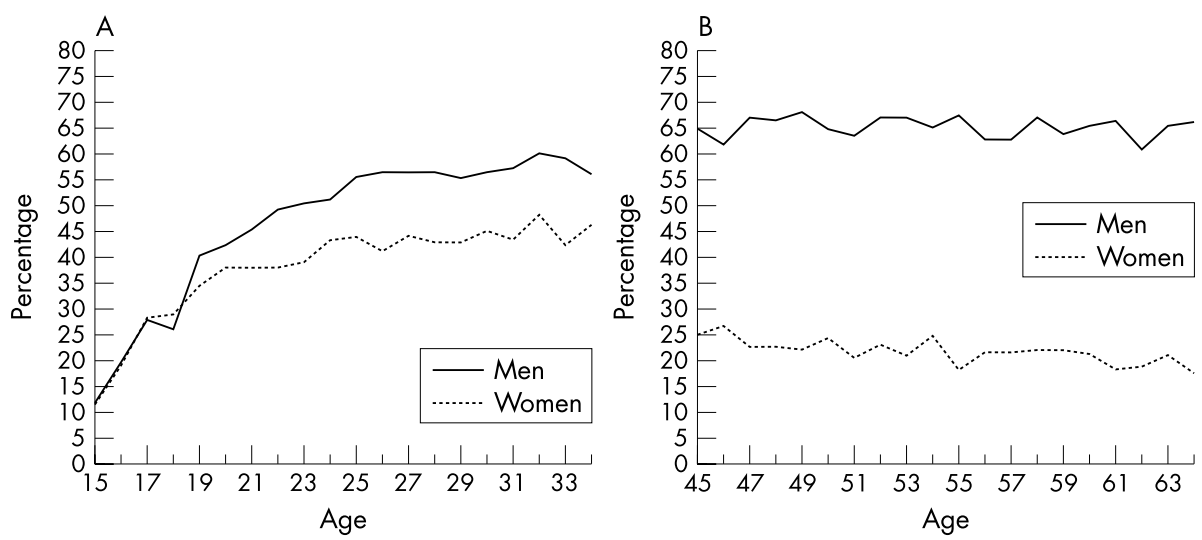

Figure 1 (A) Ever regular smoking by age and sex in cohorts born 19511980. (B) Ever regular smoking by age and sex in cohorts born 1926-1940.

Finally, to illustrate the effect of the 1976 TCA on smoking initiation, we calculated the expected ever regular smoking prevalence by sex and birth cohort in two ways: (1) the model described above including age profile, continuous cohort trend, the three dummies for the deviant cohorts, and the hypothesised effect of the TCA, and (2) the extrapolation that used the model to describe the hypothetical situation where the effects of the three dummies and of the 1976 TCA were assumed to be zero. We then compared the expected prevalence of ever regular smoking based on the model to those expected on the basis of the extrapolation.

\section{RESULTS}

A decrease in smoking from older male cohorts to younger ones was suggested by the graphic analyses. Among men, the proportion of ever regular smokers was as high as $70 \%-80 \%$ in the cohort born in 1916-30, compared with no more than $65 \%$ among those born in 1951-60 or later (fig 2). Among women a continuous increase in smoking prevalence was observed in successive cohorts (fig 3). The proportion of ever regular smokers was $15 \%-25 \%$ among women born in 191640 but reached $48 \%$ among the 1951-60 birth cohort.

In the logistic model for men, after controlling for cohort and age profile, a clear decline in the prevalence of ever smokers concurrent with the TCA was found (OR $=0.74,95 \%$ $\mathrm{CI}=0.68$ to $0.81, \mathrm{p}<0.001$; table 2 ). Among women the interaction term between the TCA and cohort trend $(\mathrm{p}<0.001)$ was included in the model, and a decline in the prevalence of ever smokers concurrent with the TCA was again clear (table 2 ). The prevalence of ever regular smoking was exceptionally high among men born in 1916-25 and in 1946-50, while it was low among men born in 1931-35. Among women, those born in 1916-25 formed an exception to the general cohort trend.

Table 3 presents the observed prevalence (corrected for the effect of non-response), the prevalence estimated by the models described in table 2 , and the prevalence expected in birth cohorts assuming that the smoking trends observed before the effect of the TCA in 1976 had continued, calculated on the basis of the extrapolation. The estimates based on the models including the effect of the TCA appear to fit rather well to the observed prevalence, calculated in three broad age intervals (19-34, 35-49, 50-64) among those cohorts for which actual prevalence data at these ages were availablethat is, for those born in $1946-80,1931-65$, and 1916-50, respectively.

Among women, a continuation of the earlier trend would have implied a dramatic increase in the prevalence of ever regular smoking in cohorts born after 1955 while among men a slow decline would have been expected. Smoking initiation in these cohorts who reached initiation age when the 1976 TCA was operational, was less common than expected based

Table 2 Variation of the prevalence of ever regular daily smoking according to age and birth cohort, and the effect of the 1976 Tobacco Control Act (TCA) by sex. For men only the main effects and for women also the interaction term between the TCA and cohort trend $(p<0.001)$ were included. Odd ratios (OR) and $95 \%$ confidence intervals $(C I)$ of logit model. Corrected for the bias attributable to declining response rate

\begin{tabular}{|c|c|c|c|c|}
\hline Variable & Men OR & $95 \% \mathrm{Cl}$ & Women OR & $95 \% \mathrm{Cl}$ \\
\hline Age-young* & 1.09 & (1.07 to 1.11$)$ & 1.05 & (1.03 to 1.07 ) \\
\hline Age-old $\dagger$ & 0.98 & (0.94 to 1.02$)$ & 0.93 & (0.89 to 0.97 ) \\
\hline Cohort (trend)‡ & 0.96 & (0.94 to 0.98 ) & $1.30 \S$ & (1.28 to 1.33 ) \\
\hline \multicolumn{5}{|l|}{ Deviant cohorts: } \\
\hline Cohort 1916-25 & 1.33 & (1.18 to 1.49 ) & 1.49 & (1.31 to 1.69$)$ \\
\hline Cohort 1931-35 & 0.88 & $(0.81$ to 0.96$)$ & 0.97 & (0.88 to 1.07 ) \\
\hline Cohort 1946-50 & 1.09 & (1.03 to 1.16 ) & 1.01 & (0.96 to 1.07 ) \\
\hline \multicolumn{5}{|l|}{ TCA 1976: } \\
\hline before & 1.00 & - & 1.00 & - \\
\hline after & 0.74 & $(0.68$ to 0.81$)$ & & \\
\hline \multicolumn{5}{|l|}{ Women } \\
\hline 1961-1965 & & & 0.45 & (0.35 to 0.57$)$ \\
\hline 1966-1970 & & & 0.34 & $(0.26$ to 0.45$)$ \\
\hline 1971-1975 & & & 0.26 & $(0.19$ to 0.36$)$ \\
\hline
\end{tabular}

*Age-young: if age $<25$ then age - young $=$ age -25 ; if age $\geqslant 25$ then age - young $=0$ (note that $O R$ gives the relative change during an age interval of one year). + Age - old: if age $\leqslant 49$ then age - old $=0$; if age $>49$ then age - old $=($ age -49$) / 5$ (note that OR gives the relative change during an age interval of five years). $\neq$ Cohort: (birth year -1950$) / 5$ (note that OR gives the relative change during a cohort interval of five years). §Before the effect of the TCA (birth cohorts born 1916-1955). 


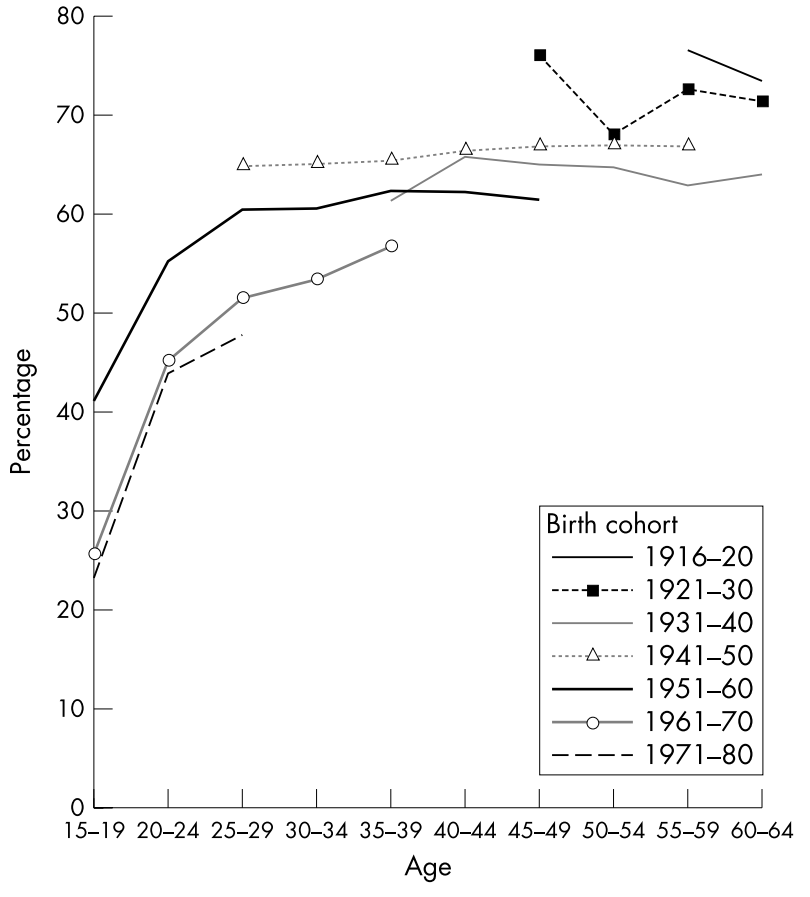

Figure 2 The proportion of ever regular male smokers by birth cohort and age.

on the extrapolation. The difference between the observed prevalence of ever regular smoking and that expected on the basis of the extrapolation, which may be taken to estimate the impact of the TCA, turned out to be about seven percentage points $(\mathrm{p}<0.001)$ among men and about 20 percentage points $(\mathrm{p}<0.001)$ among women born in 1961-65, and among the younger cohorts even more (table 3, fig 4 ).

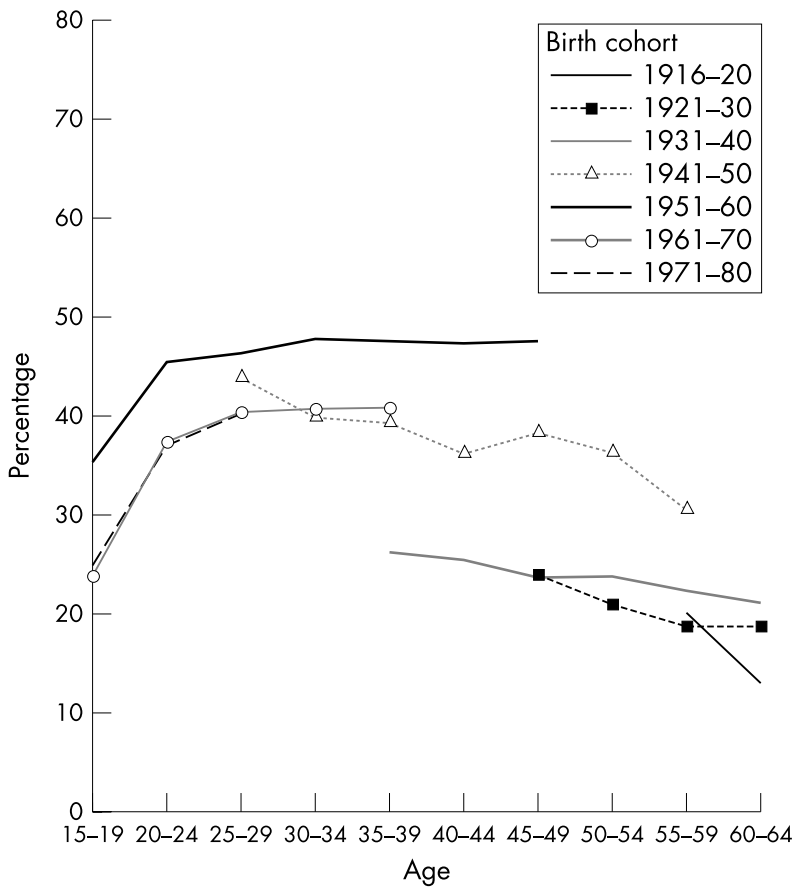

Figure 3 Proportion of ever regular female smokers by birth cohort and age.

\section{DISCUSSION}

These analyses gave important information on the dynamics of smoking in Finland. We found a rather consistent age pattern in ever regular smoking initiation. The lasting differences between birth cohorts of both men and women as regards ever regular smoking may well reflect the impact of antismoking policy measures. Smoking initiation among

Table 3 Ever regular daily smoking among men and women by five year birth cohort: the observed prevalences and those expected on the basis of the model ${ }^{*}$ and extrapolationt. Corrected for the bias attributable to declining response rate

\begin{tabular}{|c|c|c|c|c|c|c|c|c|c|}
\hline Men & $\begin{array}{l}\text { Observed } \\
\text { (\%) }\end{array}$ & $\begin{array}{l}\text { Model } \\
(\%)\end{array}$ & $\begin{array}{l}\text { Extra- } \\
\text { polation (\%) }\end{array}$ & $\begin{array}{l}\text { Model- } \\
\text { Extrapolation }\end{array}$ & Women & $\begin{array}{l}\text { Observed } \\
(\%)\end{array}$ & $\begin{array}{l}\text { Model } \\
(\%)\end{array}$ & $\begin{array}{l}\text { Extra- } \\
\text { polation (\%) }\end{array}$ & $\begin{array}{l}\text { Model- } \\
\text { Extrapolation }\end{array}$ \\
\hline \multicolumn{10}{|c|}{ Observed: age group $50-64$ year old, in the models age $=57$ year old } \\
\hline 1916-20 & 72.0 & 74.4 & 68.4 & +6.0 & 1916-20 & 13.9 & 15.6 & 11.0 & +4.6 \\
\hline $1921-25$ & 75.2 & 73.6 & 67.6 & +6.0 & $1921-25$ & 20.1 & 19.6 & 13.9 & +5.7 \\
\hline $1926-30$ & 66.6 & 66.8 & 66.8 & 0 & $1926-30$ & 19.3 & 17.4 & 17.4 & 0 \\
\hline $1931-35$ & 63.0 & 63.1 & 65.9 & -2.8 & $1931-35$ & 21.9 & 21.0 & 21.6 & -0.6 \\
\hline $1936-40$ & 64.4 & 65.0 & 65.0 & 0 & $1936-40$ & 24.3 & 26.4 & 26.4 & 0 \\
\hline $1941-45$ & 66.6 & 64.2 & 64.2 & 0 & $1941-45$ & 32.6 & 31.9 & 31.9 & 0 \\
\hline $1946-50$ & 67.0 & 65.3 & 63.3 & +2.0 & $1946-50$ & 40.9 & 38.2 & 37.9 & +0.3 \\
\hline \multicolumn{10}{|c|}{ Observed: age group $35-49$ year old, in the models age $=42$ year old } \\
\hline $1931-35$ & 63.9 & 63.8 & 66.6 & -2.8 & $1931-35$ & 21.3 & 23.0 & 23.6 & -0.6 \\
\hline $1936-40$ & 65.0 & 65.7 & 65.7 & 0 & $1936-40$ & 26.9 & 28.7 & 28.7 & 0 \\
\hline $1941-45$ & 65.9 & 64.8 & 64.8 & 0 & $1941-45$ & 35.7 & 34.4 & 34.4 & 0 \\
\hline $1946-50$ & 66.1 & 66.0 & 64.0 & +2.0 & $1946-50$ & 41.0 & 40.9 & 40.6 & +0.3 \\
\hline $1951-55$ & 63.0 & 63.1 & 63.1 & 0 & $1951-55$ & 48.3 & 47.2 & 47.2 & 0 \\
\hline $1956-60$ & 60.7 & 59.5 & 62.2 & -2.7 & $1956-60$ & 47.5 & 48.5 & 53.8 & -5.3 \\
\hline $1961-65$ & 56.7 & 53.9 & 61.3 & -7.4 & $1961-65$ & 41.8 & 40.6 & 60.3 & -19.7 \\
\hline \multicolumn{10}{|c|}{ Observed: age group 19-34 year old, in the models age $=24$ year old } \\
\hline $1946-50$ & 64.8 & 64.1 & 62.0 & +2.1 & $1946-50$ & 40.1 & 39.8 & 39.5 & +0.3 \\
\hline $1951-55$ & 62.2 & 61.1 & 61.1 & 0 & $1951-55$ & 49.2 & 46.0 & 46.0 & 0 \\
\hline $1956-60$ & 56.8 & 57.4 & 60.2 & -2.8 & $1956-60$ & 44.5 & 47.3 & 52.6 & -5.3 \\
\hline $1961-65$ & 49.9 & 51.8 & 59.3 & -7.5 & $1961-65$ & 38.4 & 39.4 & 59.2 & -19.8 \\
\hline 1966-70 & 50.0 & 50.4 & 58.4 & -8.0 & 1966-70 & 40.5 & 39.4 & 65.4 & -26.0 \\
\hline 1971-75 & 47.9 & 49.1 & 57.4 & -8.3 & $1971-75$ & 39.1 & 39.4 & 71.1 & -31.7 \\
\hline $1976-80$ & $40.5 \ddagger$ & 47.7 & 56.5 & -8.8 & $1976-80$ & $33.0 \ddagger$ & 39.4 & 76.3 & -36.9 \\
\hline
\end{tabular}

*The model: age profile + three dummies for the deviant cohorts + continuous cohort trend + TCA + TCA $\times$ continuous cohort (see table 2). tln the extrapolation the model was used so that the effects of the three dummies and the effect of the TCA were assumed to be zero. $\ddagger$ The observed smoking prevalence was lower than the estimated prevalence because almost all members in this cohort were 19-24 year old. The observed points where number of cases was less than 200 were excluded. 


\section{Key points}

- Finland has a long history of tobacco control policy measures.

- Current tobacco consumption in Finland is among the lowest in Europe.

- Disparities between birth cohorts in the prevalence of ever smoking are compatible with the assumed effects of Finland's 1976 Tobacco Control Act among both men and women.

members of the 1961 or later birth cohort was less common than among earlier birth cohorts.

Smoking prevalence is reduced by decreasing the rate of initiation and increasing the rate of cessation. Among Finnish men smoking initiation declined from earlier to later cohorts, whereas among women it increased in successive birth cohorts. The general cohort based trends in smoking prevalence identified here are quite similar to those found in cohort studies in other Western industrialised countries. ${ }^{53-25}$

The harmful effects of smoking began to impact public awareness in the late 1950s, after publication of the first large scale epidemiological studies into the association of lung cancer with smoking. ${ }^{14}$ It is widely known that adverse health effects encourage smokers to quit, but moreover society's response to this health threat is important. The antismoking climate in Finland began to shift in the 1960s, and noticeable changes had already occurred by the mid-1970s, before the TCA of 1976. Implementation of legislation builds coalitions in antismoking activities thus increasing the awareness on health effects. Smoking prevalence trends among men have been positive, contrasting with the situation among women. Similar divergence has been found in previous studies. ${ }^{522-25}$ It has been argued that the sexes differ in their response to antismoking policies. ${ }^{26}$ However, the trends in the smoking habits of birth cohorts seen in this study are compatible with the assumed effects of Finland's antismoking policy among both men and women. Among both sexes, smoking initiation in members of the cohort born in 1961 or later was less common than was expected on the basis of trends among the earlier birth cohorts as they were exposed to direct campaigns and reached the age of smoking initiation when or after the 1976 TCA came into force. It is possible that the tobacco price rise in 1975-1976 had an additional impact, especially among women who, according to previous research, are more responsive to price. ${ }^{26}$

An important question is to what extent the observed changes in smoking habits can be attributed to bias. Firstly, the differential mortality among smokers compared with non-smokers has to be considered. In some previous cohort studies on smoking the effect of selective mortality in younger birth cohorts has been estimated to be small. ${ }^{23}$ In this study a decline in the prevalence of ever smoking was observed in the oldest age groups that may partly reflect the effect of selective mortality. This phenomenon was taken into account when modelling the age profile. Anyway, the influence of selective mortality is likely to be mild in this study because in Finland overall mortality among under 65 year olds does not exceed $2 \% .{ }^{27}$

Secondly, the response rate of the survey decreased over the study period. It is well known that non-response has harmful effects on the external validity of study results. ${ }^{28} 29$ Disparities between respondents' and non-respondents' smoking histories may lead to distortions in observed smoking prevalence. In our study the prevalence of ever regular smokers was corrected on the basis of information

\section{Policy implications}

- Finland has a long history of high male smoking, and based on the harms caused by the high smoking rate, three decades long experience in the use of national tobacco control policy measures.

- Current tobacco consumption in Finland is among the lowest in Europe.

- Results of this study suggest strongly that the instruments of control codified in the Finnish tobacco law and its amendments have considerably contributed to the decrease on smoking among Finnish men, and to keeping Finnish female smoking on the lower level.

- Finnish experience may be used as a model and rationalisation for other national tobacco law reforms.

about non-respondents' smoking habits, but the influence of the correction on the results was very mild.

Thirdly, the misclassification of self reported smoking status has to be considered. In an earlier Finnish population based study, high validity of self reported smoking was

\begin{tabular}{|c|c|c|c|c|}
\hline $\begin{array}{l}\Delta 19-34 \\
\wedge 19-34\end{array}$ & $\begin{array}{l}\text { - } 35-49 \\
\text { - 35-49 } \\
\text { Observed }\end{array}$ & $\begin{array}{l}\text {-50-64 } \\
\text { - 50-64 }\end{array}$ & $\begin{array}{c}-25-49 \\
\text { 25-49 } \\
\text { Model }\end{array}$ & $\begin{array}{l}----25-49 \\
----25-49 \\
\text { Extrapolation }\end{array}$ \\
\hline
\end{tabular}

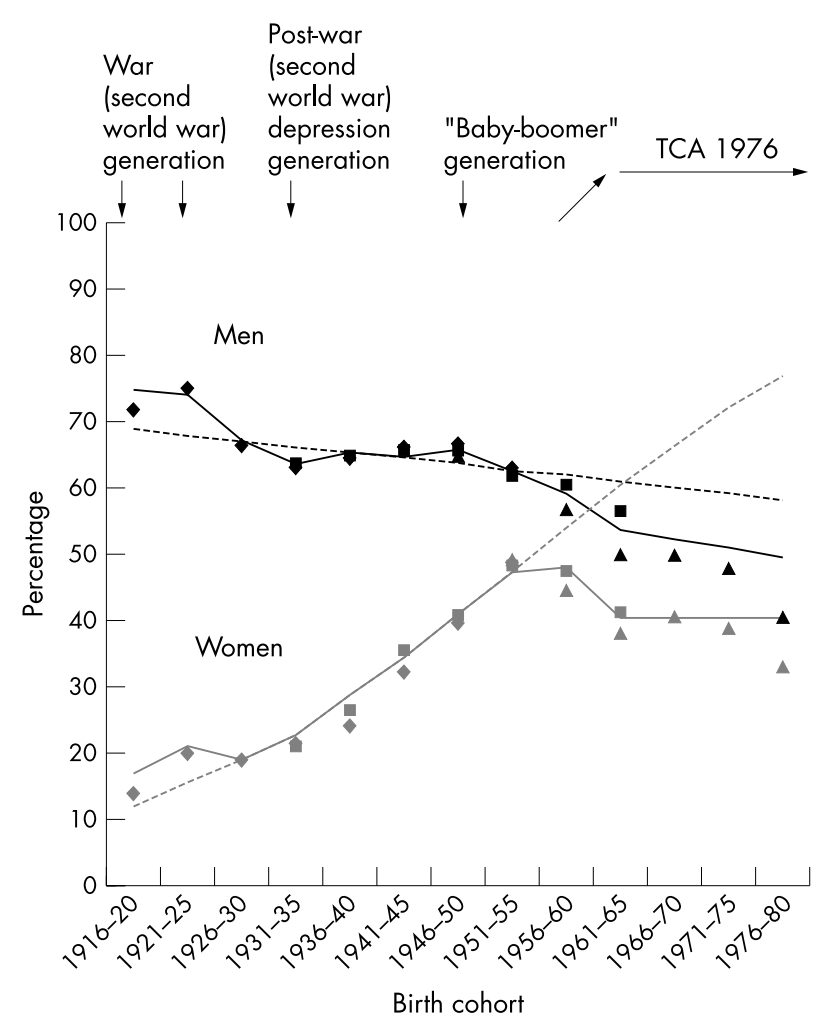

Figure 4 Ever regular daily smoking among men and women by five year birth cohort according to observed prevalence and the model estimated prevalence. The dotted lines use the model to extrapolate the hypothetical situation where the effects of the three dummies and the effect of the 1976 Tobacco Control Act (TCA) were assumed to be zero. Estimated prevalence in the model and in the extrapolation was calculated at age 42 , which represents the age interval 25-49. Corrected for the bias attributable to declining response rate. The observed points where number of cases was less than 200 were excluded. 
observed using serum cotinine concentrations to validate smoking status. ${ }^{30}$ Therefore, misclassification of smoking status attributable to self reporting is probably of minor significance.

Our study suggests that examination of smoking behaviour by birth cohort is a useful tool when evaluating the effects of antismoking policies and providing information for future public health planning. In our opinion, these findings corroborate the acceptability and potential effectiveness of antismoking policy measures in a society.

\author{
Authors' affiliations \\ S Helakorpi, T Martelin, J Torppa, K Patja, E Vartiainen, A Uutela, \\ National Public Health Institute (KTL), Helsinki, Finland \\ Funding: none. \\ Conflicts of interest: none declared.
}

\section{APPENDIX}

\section{CORRECTION FOR NON-RESPONSE}

Because the response rate of the survey declined over the study period, the resulting bias was corrected. For this purpose we used information on smoking habits from a telephone survey undertaken by the Survey Research Unit of Statistics Finland on a random sample of 1024 nonrespondents of the postal questionnaire survey of Finnish adults in 2002 (response rate 65\%). The response rate of the telephone survey was $71 \%$.

For the models the postal questionnaire data was corrected as follows: if the response rate was under $80 \%$ among men (among women 85\%) extra artificial cases were included so that the response rate increased to $80 \%$ (among women $85 \%$ ). The number of artificial cases (NRESNUM) was calculated as follows:

$$
\text { NRESNUM }=\left(\frac{0.80-\text { responserate }}{\text { responserate }}\right) \times R E S P N U M
$$

where RESPNUM was the number of respondents in the questionnaire surveys and responserate the response rate in each year for 10 year age groups by sex in the postal questionnaire surveys.

$$
\begin{aligned}
& \text { Corrected smoking prevalence }= \\
& \left(\frac{\text { SMONUM }+ \text { nonrespsmokingrate } \times \text { NRESNUM }}{\text { RESPNUM }+ \text { NRESNUM }}\right)
\end{aligned}
$$

where SMONUM was the number of smokers in the postal questionnaire survey and nonrespsmokingrate was the smoking rate in the telephone interview survey (among the nonrespondents in questionnaire surveys).

\section{REFERENCES}

1 Doll R, Peto R, Wheatley K, et al. Mortality in relation to smoking: 40 years' observations on male British doctors. BMJ 1994;309:901-11.
2 Phillips AN, Wannamethee SG, Walker M, et al. Life expectancy in men who have never smoked and those who have smoked continuously: 15 year follow up of large cohort of middle aged British men. BM 1996;313:907-8.

3 Peto R, Lopez A, Boreham J, et al. Mortality from smoking in developed countries 1950-2000. Oxford: Oxford University Press, 1994.

4 Pierce JP. International comparisons of trends in cigarette smoking prevalence. Am J Public Health 1989;79:152-7.

5 Brenner H. A birth cohort analysis of the smoking epidemic in West Germany. J Epidemiol Community Health 1993:47:54-8.

6 Lopez AD, Collshaw NE, Piha TA. A descriptive model of the cigarette epidemic in developed countries. Tobacco Control 1994;3:242-7.

7 Fernandez E, Schiaffino A, Borras JM, et al. Prevalence of cigarette smoking by birth cohort among males and females in Spain, 1910-1990. Eur J Cancer Prev 2003; 12:57-62.

8 Vartiainen E, Jousilahti P, Alfthan G, et al. Cardiovascular risk factor changes in Finland, 1972-1997. Int J Epidemiol 2000;29:49-56.

9 Rimpelä M. Tupakoinnin vähentämisessä uudenlaisiin tavoitteisiin. Huomiota myös haitta-ainealtistuksiin. Sosiaalinen aikakauskirja 1978;72:11-19.

10 Rimpelä M. Aikuisväestön tupakointitavat Suomessa 1950-1970-luvvilla, [Adult use of tobacco in Finland]. Kansanterveystieteen julkaisuja M. Tampere: University of Tampere, 1978.

11 Rahkonen O, Berg MA, Puska P. The development of smoking in Finland from 1978 to 1990. Br J Addict 1992;87:103-10.

12 Helakorpi S, Patja K, Prättälä R, et al. Health behaviour and health among Finnish adult population, Spring 2001 [in Finnish with English summary]. Helsinki: Publication of National Public Health Institute, B16/2001.

13 Corrao MA, Guindon GE, Sharma N, et al. Tobacco control country profiles. Atlanta, GA: The American Cancer Society, 2000.

14 Surgeon General's Report. US Public Health Service. Smoking and Health Report of the Advisory Committee to the Surgeon General of the public Health Service. Washington: US Department of Health, Education and Welfare, Public Health Service, Center for Disease Control, 1964.

15 Leppo K, Vertio H. Smoking control in Finland: a case study in policy formulation and implementation. Health Promotion 1986;1:5-16.

16 Puska P, Korhonen HJ, Uutela A, et al. Anti-smoking policy in Finland. In: Puska P, Elovainio L, Vertio H, eds. Smoke free Europe: a forum for networks. Jyväskylä: Gummerus, 1997.

17 Tobacco Network. Act on measures to reduce tobacco smoking. http:// www.tupakka.org/ (accessed 18 Jun 2003).

18 Leppo K, Puska P. Tobacco control in Finland. Suomen Lääkärilehti 2003;58:2953-7

19 Pekurinen $M$, Valtonen $\mathrm{H}$. Price, policy and consumption of tobacco: the Finnish experience. Soc Sci Med 1987;25:875-81.

20 Puska P, Tuomilehto J, Nissinen A, et al. The North Karelia Project, 20 years results and experiences. Helsinki: Helsinki University Printing House, 1995

21 Martelin T. The development of smoking habits according the Survey Data in Finland [in Finnish with English summary]. Helsinki: Publications of the National Board of Health, Health Education, 1984.

22 Laaksonen M, Uutela A, Vartiainen E, et al. Development of smoking by birth cohort in the adult population in eastern Finland 1972-97. Tobacco Control 1999:8:161-8.

23 Harris JE. Cigarette smoking among successive birth cohort of men and women in the United States during 1900-80. J Natl Cancer Inst 1983;71:473-9.

24 Birkett NJ. Trends in smoking by birth cohort for births between 1940 and 1975: a reconstructed cohort analysis of the 1990 Ontario Health Survey. Prev Med 1997;26:534-41.

$25 \mathrm{Kemm}$ JR. A birth cohort analysis of smoking by adults in Great Britain 1974-1998. J Public Health Med 2001;23:306-11.

26 Townsend J, Roderick P, Cooper J. Cigarette smoking by socioeconomic group, sex, and age: effects of price, income, and health publicity. BMJ 1994;309:923-7.

27 Statistics Finland. Causes of death 2001. Health 2002:3. Helsinki: Statistics Finland, 2002.

28 Van Loon AJM, Tiihuis M, Picavet HSJ, et al. Survey non-response in the Netherlands. Effects on prevalence estimates and associations. Ann Epidemiol 2003; 13:105-10.

29 Hill A, Roberts J, Ewings P, et al. Non-response bias in a lifestyle survey. J Public Health Med 1997; 19:203-7.

30 Vartiainen E, Seppala T, Lillsunde P, et al. Validation of self reported smoking by serum cotinine measurement in a community based study. J Epidemiol Community Health 2002;56:167-70 